9. Easton K, Morgan T, Williamson M. Medication safety in the community: a review of the literature. Sydney: National Prescribing Service; 2009.

www.nps.org.au/research_and_evaluation/current_research/ medication_safety_community [cited 2011 Nov 7]

10. Colebatch KA, Marley J, Doecke C, Miles H, Gilbert A. Evaluation of a patient event report monitoring system. Pharmacoepidemiol Drug Saf 2000;9:491-9.

11. Routledge PA, O'Mahony MS, Woodhouse KW. Adverse drug reactions in elderly patients. Br J Clin Pharmacol 2004;57:121-6.

12. Blendon RJ, Schoen C, DesRoches C, Osborn R, Zapert K. Common concerns amid diverse systems: Health care experiences in five countries. Health Aff (Millwood) 2003;22:106-21.

13. Schoen C, Osborn R, Huynh PT, Doty M, Davis K, Zapert K, et al. Primary care and health system performance: Adults' experiences in five countries. Health Aff 2004;Suppl web exclusives:W4-487-503.

14. Gilbert AL, Roughead EE, Beilby J, Mott K, Barratt JD. Collaborative medication management services: improving patient care. Med J Aust 2002;177:189-92.

15. Roughead EE, Barratt JD, Ramsay E, Pratt N, Ryan P, Peck R, et al. The effectiveness of collaborative medicine reviews in delaying time to next hospitalisation for patients with heart failure in the practice setting: results of a cohort study. Circ Heart Fail 2009;2:424-8.

16. Roughead EE, Barratt JD, Ramsay E, Pratt N, Ryan P, Peck R, et al. Collaborative home medicines review delays time to next hospitalization for warfarin associated bleeding in Australian war veterans. J Clin Pharm Ther 2011;36:27-32.
17. Gill SS, Mamdani M, Naglie G, Streiner DL, Bronskill SE, Kopp A, et al. A prescribing cascade involving cholinesterase inhibitors and anticholinergic drugs. Arch Intern Med 2005;165:808-13.

18. Vegter S, de Jong-van den Berg LT. Misdiagnosis and mistreatment of a common side-effect-angiotensin-converting enzyme inhibitor-induced cough. Br J Clin Pharmacol 2010;69:200-3.

19. Mallet $L$, Spinewine $A$, Huang $A$. The challenge of managing drug interactions in elderly people. Lancet 2007;370:185-91.

20. Corrao G, Botteri E, Bagnardi V, Zambon A, Carobbio A, Falcone $C$, et al. Generating signals of drug-adverse effects from prescription databases and application to the risk of arrhythmia associated with antibacterials. Pharmacoepidemiol Drug Saf 2005;14:31-40.

21. Tsiropoulos I, Andersen M, Hallas J. Adverse events with use of antiepileptic drugs: a prescription and event symmetry analysis. Pharmacoepidemiol Drug Saf 2009;18:483-91.

22. Bytzer $P$, Hallas J. Drug-induced symptoms of functional dyspepsia and nausea. A symmetry analysis of one million prescriptions. Aliment Pharmacol Ther 2000;14:1479-84.

23. Rochon PA, Gurwitz JH. Drug therapy. Lancet 1995;346:32-6.

Conflict of interest: none declared

\title{
Letters
}

The Editorial Executive Committee welcomes letters, which should be less than 250 words. Before a decision to publish is made, letters which refer to a published article may be sent to the author for a response. Any letter may be sent to an expert for comment. Letters are usually published together with their responses or comments in the same issue. The Editorial Executive Committee screens out discourteous, inaccurate or libellous statements and sub-edits letters before publication. The Committee's decision on publication is final.

\section{Hyperferritinaemia without positive HFE gene mutation}

Editor, - I read the article about testing for HFE-related haemochromatosis with interest (Aust Prescr 2011;34:73-6). Over the last 10 years I have ordered ferritin tests in over 1211 individual patients -229 of them were found to have abnormally elevated ferritin levels. Haemochromatosis gene testing was ordered for 120 of them and there were 47 positive results. This means a significant cohort of patients with elevated ferritin do not have a positively identified mutation. My casual observation seems to give the impression that a significant number of these patients are Asian people.

Anecdotally, diabetes and lipid control in many of these patients improved when they started donating blood regularly.
My hypothesis is that:

- there are more genotypes yet to be discovered which are responsible for elevated ferritin levels in Asian people

- this (undetected and untreated) elevated ferritin may deposit in the pancreas and liver, and to some extent contributes to the high rate of diabetes and fatty livers that are so prevalent in Asian people.

Unfortunately, this is just a hunch and I do not have the detailed breakdown of these tests.

Chenault Doug Lee

General practitioner

Erindale Medical Practice, ACT 
Professor Crawford, Dr Stuart and Dr St John, authors of the article, comment:

We thank Dr Lee for his interesting comments and important observations. He has raised a number of issues that are worthy of further consideration. Whilst non-HFE related iron overload is uncommon, some cases have been described in Asian patients.

Our research team has methodology to sequence many genes involved in iron metabolism, and we would be happy to assist Dr Lee (and other clinicians) to define the exact nature of the genetic defect in his Asian patients who do not carry conventional mutations in the HFE gene.

However, as Dr Lee infers, the cause of the elevated serum ferritin concentration in the majority of his Asian patients is hepatic necroinflammation, often due to non-alcoholic fatty liver disease. The growing frequency of this problem probably reflects increased exposure of his patients to a Western diet rich in carbohydrates and saturated fats. Dr Lee infers that his patients benefit from venesection, and there is some evidence to support an improvement in insulin resistance associated with such therapy. There is also recent evidence of a strong association between altered iron metabolism and lipid metabolism. However, the benefit of venesection in patients with non-alcoholic fatty liver disease, elevated serum ferritin concentration and heterozygosity for HFE mutations in relation to lipid profiles, cardiovascular mortality and liver histology is controversial and awaits definitive study.

\section{Managing aggressive and violent patients}

Editor, - We have some concerns about the approach to sedation of patients with aggression and violence suggested by Professor Fulde and Associate Professor Preisz

(Aust Prescr 2011;34:115-8). Large numbers of patients require parenteral sedation with physical containment which can be hazardous to staff and requires a standardised approach.

Recent research supports the use of different drugs and initial intramuscular sedation for most patients. One study demonstrated that the duration of acute behavioural disturbance was reduced when intramuscular sedation was employed. ${ }^{1}$ Intravenous sedation requires sufficient staff to restrain the patient, otherwise it is dangerous with the risk of needle stick or physical injury. However although intramuscular midazolam is used most commonly, recent evidence demonstrates that it is unpredictable due to overor under-sedation. ${ }^{2}$ A controlled trial found that $10 \mathrm{mg}$ intramuscular midazolam caused adverse events in $28 \%$ of patients compared to $6 \%$ with droperidol. ${ }^{2}$

Only the antipsychotics olanzapine and haloperidol were suggested for sedation in the article. Haloperidol is not very sedative and has a black box warning by the US Food and Drug Administration (FDA) for confirmed reports of QT prolongation and torsades des pointes. Parenteral olanzapine has never been shown to be effective in the emergency department setting. ${ }^{3}$ Droperidol is safer and more effective for sedation of acute behavioural disturbance in the emergency department. ${ }^{2}$ It has been used extensively and rarely causes over-sedation. There have been concerns about QT prolongation and torsades des pointes. Despite an FDA black box warning this has not been confirmed in a systematic review. ${ }^{4}$

We now routinely use $10 \mathrm{mg}$ intramuscular droperidol for initial sedation and repeat the dose after 15 minutes if required. In 412 patients sedated this way, $66 \%$ became sedated with one dose. Minor adverse events occurred in $5.5 \%$ of patients but no patient had QT prolongation.

Geoffrey K Isbister

Emergency Department

Leonie A Calver

Department of Clinical Toxicology and Pharmacology

Calvary Mater Newcastle Hospital, NSW

\section{References}

1. Calver LA, Downes MA, Page CB, Bryant JL, Isbister GK. The impact of a standardised intramuscular sedation protocol for acute behavioural disturbance in the emergency department. BMC Emerg Med 2010;10:14.

2. Isbister GK, Calver LA, Page CB, Stokes B, Bryant JL, Downes MA. Randomized controlled trial of intramuscular droperidol versus midazolam for violence and acute behavioral disturbance: the DORM study. Ann Emerg Med 2010;56:392-401.e1.

3. Knott JC, Isbister GK. Sedation of agitated patients in the emergency department. Emerg Med Australas 2008;20:97-100.

4. Kao LW, Kirk MA, Evers SJ, Rosenfeld SH. Droperidol, QT prolongation, and sudden death: what is the evidence? Ann Emerg Med 2003;41:546-58.

\section{Improving Aboriginal and Torres Strait Islander people's access to the Pharmaceutical Benefits Scheme}

Editor, - While the article by Noel Hayman (Aust Prescr 2011;34:38-40) is factual and highlights the benefit of the Closing the Gap (CTG) Pharmaceutical Benefits Scheme (PBS) incentive payment scheme, it does not highlight the gaps that were not addressed in the implementation of the scheme.

In many locations there is very limited access to mainstream general practitioner services or to an Aboriginal health service and many of the 'general practitioner' services are provided by state hospitals that have the right to prescribe PBS-subsidised medications.

These state hospitals provide general practitioner services and provide PBS prescriptions to Aboriginal and Torres Strait 
Islander patients but community pharmacy cannot provide a subsidised service as the CTG initiative does not include state hospital services. In August 2010, the CTG PBS initiative was expanded to include prescriptions written by specialists but state hospital doctors were still excluded.

Many Aboriginal and Torres Strait Islander patients become very confused because when they access a mainstream general practitioner they can receive a CTG prescription which is subsidised for them in community pharmacy, but if they access the hospital service after hours the PBS prescription they receive is not subsidised and they have to pay the full PBS price. Many general practitioner practices no longer provide after hours or weekend services so these patients are forced to use the state hospital services outside of normal practice hours.

This disparity of access has been discussed many times and is still a major issue in providing optimal care for Aboriginal and Torres Strait Islander people.

\section{Karalyn J Huxhagen}

Pharmacist

Mackay, Qld

Associate Professor Hayman, author of the article, comments:

It is not uncommon after the implementation of government policy that unexpected gaps in delivery become apparent. I have been aware of the problem that Karalyn Huxhagen highlights for some time.

Another gap I have identified is in medical services that are not accredited in quality of practice and therefore their patients cannot access the CTG PBS initiative. While this may be satisfactory in urban settings it is very problematic in rural and remote areas where unaccredited medical services are common. Aboriginal and Torres Strait Islander patients from these clinics are disadvantaged causing the disparity of access pointed out by Karalyn Huxhagen. The CTG PBS policy causes conflict where there is a combination of accredited and non-accredited services in a rural or remote area. Aboriginal patients are forced to go to the accredited service to access the CTG PBS program, leaving their preferred doctor of choice. This leads to disjointed care.

The Department of Health and Ageing is committed to an evaluation process of all CTG programs. Sentinel sites have been established across Australia to evaluate CTG initiatives. I have personally given feedback on the problems outlined in this response. The evaluation process will continue over the next year and hopefully all gaps identified will influence a change in policy, particularly those that will correct the gaps in service delivery and access for all Aboriginal and Torres Strait Islander peoples.

\section{Anaphylaxis wallchart}

Editor, - I write in response to the anaphylaxis wallchart ${ }^{1}$ and would like to comment on the impracticality of advising Epipen as an alternative to adrenaline ampoules and syringe. I am sure the Editorial Committee of Australian Prescriber are aware that Epipen is only subsidised when it is prescribed by clinical immunologists, paediatricians and respiratory physicians but not by other health professionals. Other doctors must purchase it privately at a cost of $\$ 104$. Because it does not last long, replacing stock is costly. Even when I was a member of the Australasian Society of Clinical Immunology and Allergy, I could not prescribe Epipen on authority as I am a dermatologist. It did not matter that some of my patients with eczema had a severe peanut or latex allergy, I still was not allowed to write an authority prescription.

Perhaps if Epipen was available as a doctor's bag item under the Pharmaceutical Benefits Scheme (PBS), ${ }^{2}$ health professionals may have better access. It would make sense to have Epipen as an alternative on the wallchart, but until such time, it is too expensive to place it as a viable alternative to adrenaline ampoules for health professionals.

\section{References}

1. Anaphylaxis: emergency management for health professionals [wall chart]. Aust Prescr 2011;34:124.

2. Emergency drug supply. Pharmaceutical Benefits Scheme. www.pbs.gov.au/browse/doctorsbag [cited 2011 Nov 15]

Margaret Oziemski

Dermatologist, Dermus Medical

Brisbane, Qld

The Australasian Society of Clinical Immunology and Allergy comments:

Both Epipen and Anapen are classified as Schedule 3 medicines and are available without prescription at full retail price or through PBS authority prescriptions. As determined by Medicare, PBS regulations stipulate that initial authority prescriptions are given when risk and clinical need has been assessed by, or in consultation with, a clinical immunologist, allergist, paediatrician or respiratory physician or after hospital or emergency department discharge for acute allergic anaphylaxis treated with adrenaline.

Any medical practitioner can prescribe an adrenaline autoinjector in consultation with one of the specialists listed above, initially by telephone. The patient should then be referred to an allergy specialist for assessment. Renewal prescriptions for adrenaline autoinjectors can be provided by any medical practitioner, and both adults and children at risk of anaphylaxis are eligible for up to two adrenaline autoinjectors per authority prescription. 